\title{
Prefabricated, Low Cost and Ready to Install Water Treatment Unit Operation Modules for the Townships of Sri Lanka
}

\author{
S. Sumanaweera and G. G. N. Gunawardena
}

\begin{abstract}
There is a rising demand for affordable, easy to build and movable type water treatment unit operation modules mainly due to river intake problems induced by poor environmental management. This is an effort to reintroduce conventional water treatment modules using low cost construction material and prefabrication techniques to construct in lesser time and to move the modules when required to suit the problems of varying nature. Basically three modules tube settler, chlorine contact tank and rapid sand filter are discussed. Construction methodology and material selection are the key features concentrated towards achieving the objectives. These modules have been successfully tested at Pugoda and Mahiyangana water supply schemes of the National Water Supply and Drainage Board (NWSDB) and found to be a solution for many prevailing problems.
\end{abstract}

Keywords: Tube Settler, Chlorine contact tank, rapid sand filter.

\section{Introduction}

It has been identified that the Sri Lankan water sector needs rapid expansion to achieve millennium development goals declared by the United Nations in the year 2000, which envisages all citizens to have access to safe water sources for domestic consumption by the year 2025. The corporate strategies of the NWSDB focus on achieving above goals at affordable and sustainable manner. In Sri Lanka 76 percent of the population have access to safe drinking water with 31 percent having access to pipe borne water. NWSDB maintains 295 water supply schemes throughout the Island. Many of these water supply schemes are facing challenges on sustainability due to environmental problems such as river bed lowering and river flow diversions mainly due to sand mining. Sand mining causes rapid changes in river bed conditions destroying infiltration galleries and shallow wells at river banks increasing the need for more treatment to produce drinking quality water. Further the change of river basin characteristics due to urbanization and industrialization aggravates this problem. Increasing demand to treat surface water due to above reasons and lack of funds to implement enhanced water treatment facilities are the major problems encountered at present. The research and development unit of the NWSDB proposes low cost easy to construct and movable treatment modules as an immediate remedy to this problem. Utilization of local material and skills is the key to sustainability of this strategy.

\section{Emerging Surface Water Treatment needs in Sri Lanka}

NWSDB has been practicing conventional water treatment unit operations for treatment of surface water for drinking purposes. Aeration, flash mixing, flocculation, sedimentation, sand filtration and disinfection are the basic unit operations practiced. The water treatment methodologies practised by NWSDB maintained schemes vary from disinfection alone to selected conventional unit operations to suit the quality of specific raw water. Lack of investment and attention on environmental quality management is resulting in rapid changes of hydrodynamic conditions over the land contributing to water scarcity with respect to both quantity and quality. This context increases the need for implementing more water treatment unit operations. A high demand for water treatment unit operation modules at township level exists due to the status of partial or no treatment in some of the schemes and

Eng. S. Sumanaweera, B.Sc. Eng. (Moratuwa), C. Eng., MIE (Sri Lanka), M.Eng. (AIT). Assistant General Manager (Research \& Development), National Water Supply and Drainage Board, Sri Lanka. Eng. G. G. N. Gunawardena, P.G.Dip. (Moratuwa), C. Eng., MIE (Sri Lanka), , Assistant General Manager (Operations), National Water Supply and Drainage Board, Sri Lanka. 
rising water treatment demand due to environmental quality management problems.

\section{Problems identified}

The content presented below is based on solutions proposed for two problems NWSDB encountered at Pugoda and Mahiyangana township water supply schemes.

At Pugoda the source is Kelani river, only partial treatment, namely rapid sand filtration and disinfection were the treatment available which lead to consumer complaints of bad water quality. The capacity of Pugoda plant is about 500 cubic meters per day. Pugoda raw water quality is reported as turbidity varying from 10-100 NTU and colour in the range 40-80 units. At Mahiyangana the problem was the presence of high concentration of Manganese in the range of $0.2 \mathrm{mg} / \mathrm{L}$ in Mahaweli river water in addition to the presence of high turbidity and colour in the ranges of 20-80 NTU and 50-120 units respectively. The treatment available was intake well filtration combined with disinfection by chlorination which lead to formation of black deposits in the distribution. The demand of the Mahiyangana township is about 2000 cubic meters per day. The challenge was to provide quick solutions to these problems. The Research and Development section of the NWSDB determined to solve these problems could foresee that a typical traditional solution would take about one year to reach completion. One quick option was to go for a package style water treatment plant.

\subsection{The capital investment}

The NWSDB experience to date is that the imported package treatment plants may contain design problems and high operational costs which are difficult to be foreseen at bid evaluation stages. The high capital cost associated with these plants is a main drawback. Damages caused to sophisticated control systems of these plants by lightening are also contributing to the high operational costs.

Table 1 below compares the capital investment required for locally developed and recently imported package style water treatmient plants. The costs of Pugoda and Mahiyangana plants are compared with costs predicted from recently imported treatment plants from Europe.
The imported plants look very impressive and complete. However there are associated problems such as high maintenance costs and need of special skills and materials for maintenance.

Table 1 - Capital investment comparison of imported and locally developed package style water treatment plants

\begin{tabular}{|c|c|c|}
\hline $\begin{array}{c}\text { Capacity } \\
\text { (Cubic meters/ } \\
\text { day) }\end{array}$ & $\begin{array}{c}\text { European } \\
\text { plants } \\
\text { (Rs. Millions) }\end{array}$ & $\begin{array}{c}\text { Locally } \\
\text { developed } \\
\text { plants } \\
\text { (Rs. Millions) }\end{array}$ \\
\hline 500 & 20 & 6 \\
2000 & 100 & 21 \\
\hline
\end{tabular}

On the other hand, locally developed plants look crude but the maintenance costs are acceptable and not much problems encountered with skills and materials needed for maintenance as minor details of these plants are well known to us.

\subsection{Affordability}

Table 1 reveals that about 2500 house connections could be provided by an investment of Rs 21 Million which implies a capital investment of about Rs 8,500 per household for a full treatment facility excluding the distribution system. This amount is much affordable than 4 to 5 times higher investment required on an imported treatment plant. If this type of low cost options are implemented there is a possibility of raising funds out of consumers themselves rather than seeking loans in foreign currency.

Another achievement is the construction time. The required construction period for 500 cubic meters per day capacity Pugoda plant and 2000 cubic meters per day capacity Mahiyangana plant is only about three months and four months respectively. There is scope for further reduction of construction time by improving prefabrication methodology.

\subsection{Sustainability through local workmanship}

To achieve the ultimate objective of sustainability and affordability, development of our own products utilizing modern technology is vital. There should be efforts in this direction over a along period to achieve success. In other 
words purchasing finished products alone is not a successful means of development as there will be associated hidden problems which are sometimes costly to solve. Efforts demonstrated below are few moves towards the goal of improving local technology. It is believed that continuation of this kind of efforts will definitely lead to achieve technological excellence in the future. These products will help to lower the operation and maintenance cost to a minimum.

\section{Details of the solutions}

So far three unit operation modules have been developed. They are sedimentation tank incorporating tube settler technology, a chlorine contact tank and a rapid sand filter unit. The latter two units are constructed using 10 cubic meter capacity Poly-Ethylene (PE) tanks.

\subsection{Sedimentation tank}

This unit follows flash mixing and flocculation steps in conventional water treatment process. A plain sedimentation tank for 2000 cubic meters per day capacity water treatment needs about 70 square meters of land. But if tube settler technology is used the plan area requirement for sedimentation tank would be about 15 square meters only. This $79 \%$ lower land requirement for a sedimentation tank is vital for a new plant to be located in a congested small town and also it is a very effective means for upgrading an existing treatment plant. Figure 8 shows river water treatment plant at Pugoda which is a backyard construction. Tube settling is not a new technology. It has been practiced for about 40 years [1]. A main difficulty in building a tube settler is bundling tubes. Some producers use fabricated tube modules or assembled plate modules for this purpose. In this work it was able to produce a tube module using $50 \mathrm{~mm}$ diameter $1 \mathrm{~m}$ long Poly Vinyl Chloride (PVC) conduit pipes bundled at 60 degree inclination to the horizontal [2]. The modules were placed inside a mild steel container made out of $3 \mathrm{~mm}$ thick mild steel plates with proper hydraulics to achieve $6.1 \mathrm{~m} / \mathrm{h}$ overflow rate [3]. The mild steel container was sand blasted and painted with a food grade marine paint coating system for corrosion protection.

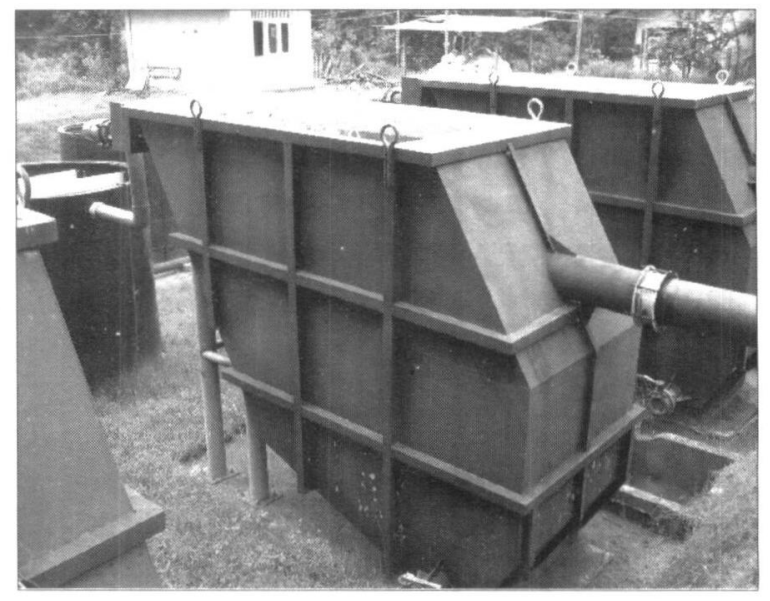

Figure 1: Tube settler at Mahiyangana

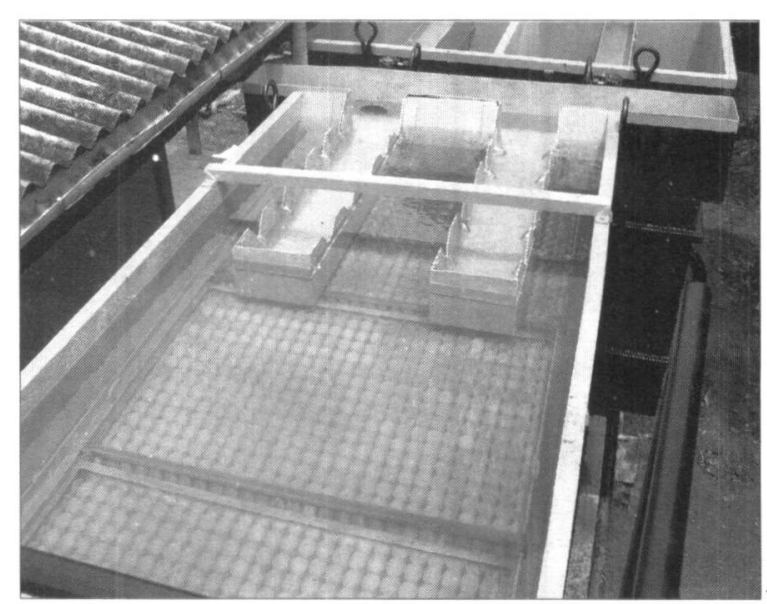

Figure 2: Tube settler in operation at Pugoda

It is expected that this tube settler module will last for more than 10 years. Figure 1 shows a tube settler of 500 cubic meters per day capacity built at Mahiyanagana and Figure 2 shows similar capacity tube settler at Pugoda in operation. A module of tubes used for the tube settler is shown in Figure 3.

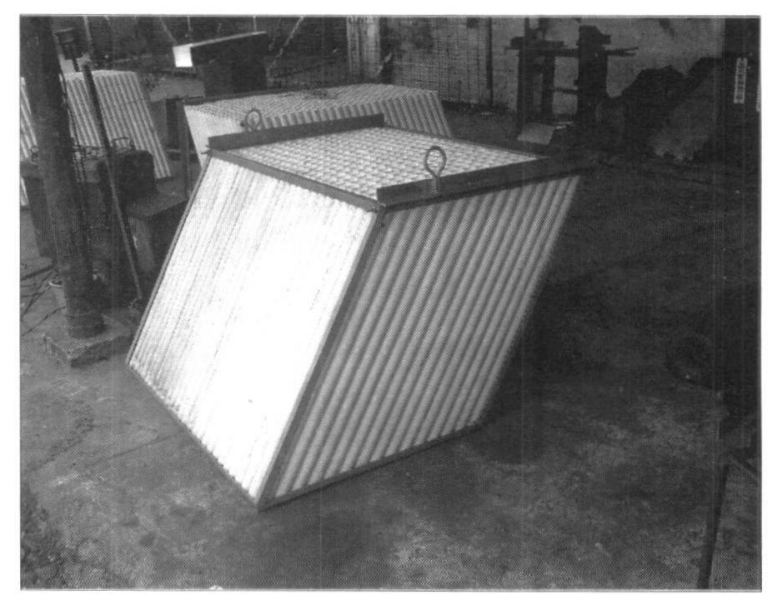

Figure 3: A module of tubes for the tube settler 


\subsection{Chlorine contact tank}

Chlorine contact tank is useful for disinfection or oxidation processes in water treatment. In our project, such tank is used for oxidation for Manganese removal at the Mahiyangana water supply scheme. In Mahiyangana Manganese levels are in the range of $0.1-0.2 \mathrm{mg} / \mathrm{L}$ which is higher than the WHO guideline values $0.05 \mathrm{mg} /$ L [4]. According to WHO Guidelines for drinking water quality, the presence of Manganese in drinking water will be objectionable to consumers if it is deposited in water mains and causes water discolouration. Concentrations below $0.05-0.1 \mathrm{mg} / \mathrm{L}$ are usually acceptable to consumers but may sometimes still give rise to the deposition of black deposits in water mains over an extended period. Source of Manganese in surface waters is rocks and soil. It is generally present in the form of $\mathrm{Mn}^{2+}$ as Manganous Bicarbonate, Manganous Chloride or Manganous Sulphate [5]. $\mathrm{Mn}^{2+}$ is oxidized to $\mathrm{Mn}^{4+}$ to yield $\mathrm{MnO}_{2}$ which is a colloidal oxide. Manganese Dioxide is characterized by dark brownish-yellow colour which is readily noticeable in water even in very low concentrations. Sorption of $\mathrm{Mn}^{2+}$ by the oxide makes the oxide a hydrous product of indefinite stoichiometric composition. Neglecting possible degree of hydration its formula therefore could be $\mathrm{MnO}_{(1+\mathrm{x})}$, where $\mathrm{x}$ can vary from 0.1 to 0.95 [6]. Further, literature suggests high $\mathrm{pH}$ in the range of 8.3 to 8.5 for effective $\mathrm{Mr}_{1}{ }^{2+}$ oxidation [5]. The reaction will be slow at $\mathrm{ph} 7$ than at $\mathrm{pH}$ 8.5 [7]. Chlorine is used in this case as the oxidant. The stoichiometric reaction for Manganese precipitation is as follows.

$\mathrm{Mn}^{2+}+\mathrm{HOCl}+\mathrm{H}_{2} \mathrm{O} \rightarrow \mathrm{MnO}_{2}(\mathrm{~s})+\mathrm{Cl}^{-}+3 \mathrm{H}^{+}$

Considering all these facts and the practical experiences, 30 minute Chlorine contact at suitable $\mathrm{pH}$ and subsequent rapid sand filtration is identified as means of successful removal of Manganese in drinking water. Oxidation and sorption are the processes involved in this treatment.

To make the construction faster, 10 cubic meter capacity PE tank was chosen for the Chlorine contact module. This tank provides 30 minute contact time for 500 cubic meters per day capacity treatment. In this tank water is allowed to flow in a repeated up and down path through vertical plates fixed inside the tank at $400 \mathrm{~mm}$ spacing. $75 \mathrm{~mm}$ thick Hora or Kumbuk timber plates are preferred for the plate construction. Figures 4 \& 5 shows the details of Chlorine contact tank.

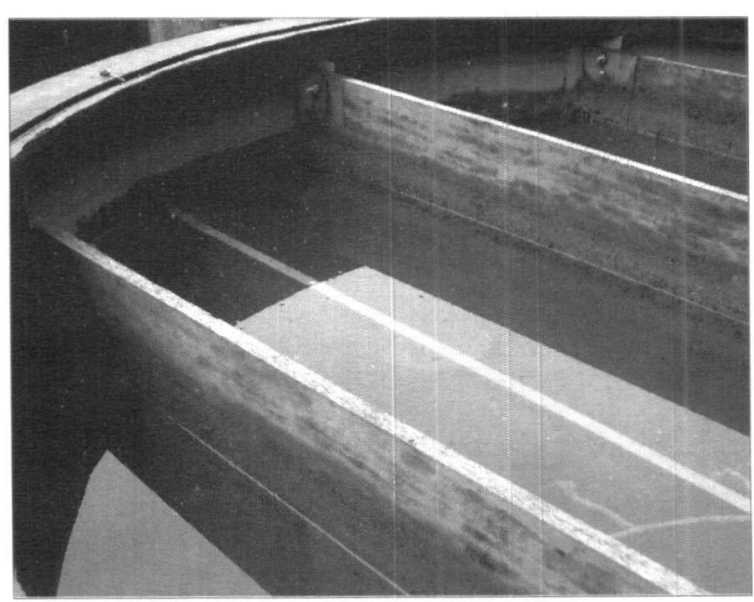

Figure 4: Inside view of the Chlorine contact tank

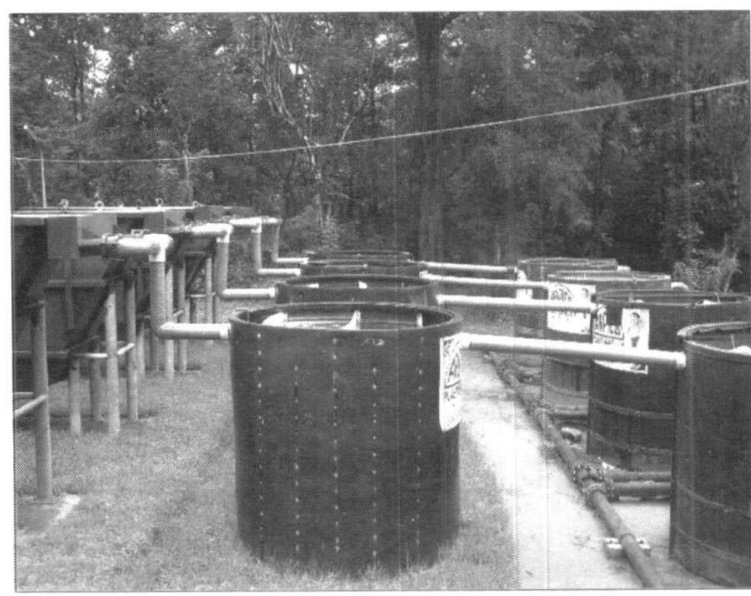

Figure 5: Chlorine contact tank fixed in between tube settler and rapid sand filter units

\subsection{Rapid sand filter}

A 10 cubic meter capacity PE tank was used to make a rapid sand filter of 500 cubic meters per day capacity. One such filter unit needs about 250 nozzles. Figure 6 shows the nozzle fixing arrangement using $63 \mathrm{~mm}$ PVC pipes inside the PE tank. After fixing the nozzles, approximately $75 \mathrm{~mm}$ thick layer of $25-40 \mathrm{~mm}$ pebbles was placed to cover the base pipes of the nozzles. Inlet water flow and backwash water collection is done via a channel made out of PVC pipes as shown in Figure 7. Filter sand with effective size $0.8 \mathrm{~mm}$ and a uniformity coefficient of 1.5 was used to make a sand bed of $800 \mathrm{~mm}$ thick. Rapid sand filter is designed for $6 \mathrm{~m} / \mathrm{h}$ filtration rate and $37 \mathrm{~m} / \mathrm{h}$ backwash rate. 


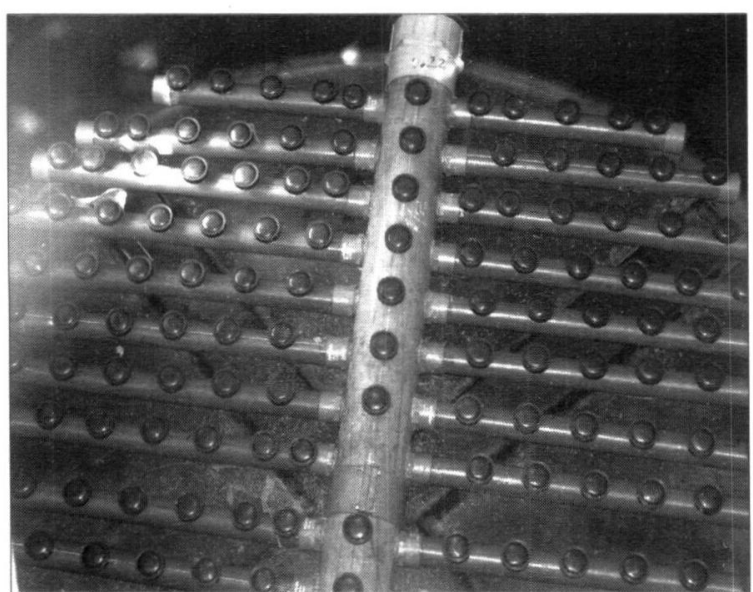

Figure 6: Nozzles of the rapid sand filter fixed inside the 10 cubic meter capacity PE tank

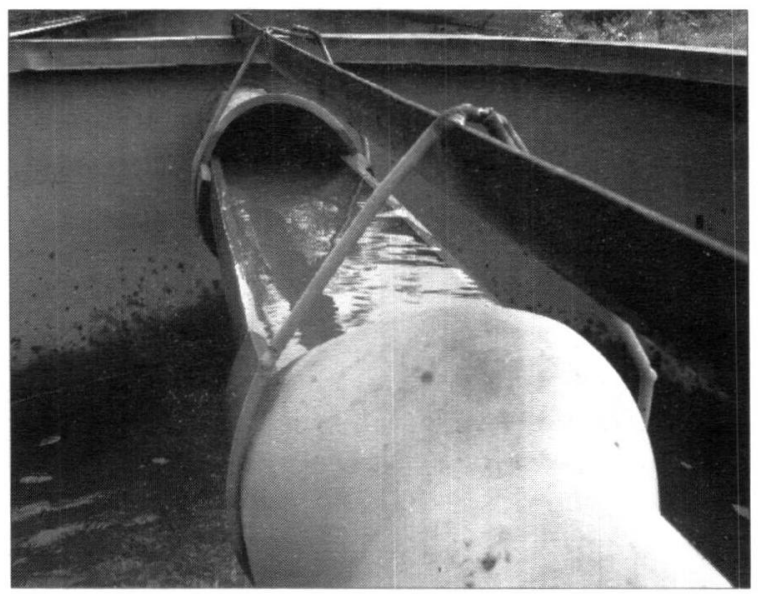

Figure 7: Rapid sand filter in operation

\subsection{Treatment efficiency}

According to the site records from Mahihyangana, the tube settler is 75 to $95 \%$ efficient in turbidity removal. The chlorine contact tank combined with rapid sand filter is 80 to $95 \%$ efficient in removing Manganese and the rapid sand filter shows 50 to $75 \%$ turbidity removal efficiency. Figure 8 shows how the new plant reduced the Manganese concentration to below $0.05 \mathrm{mg} / \mathrm{L}$.

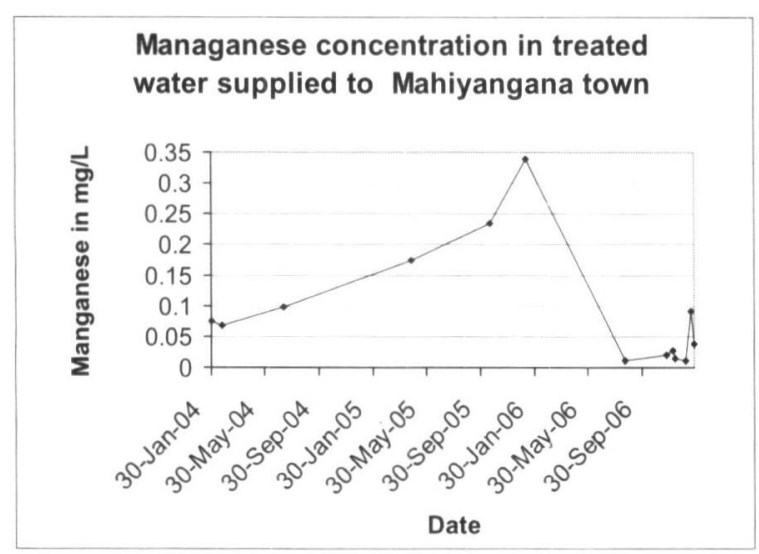

Figure 8: Improved Manganese removal after the treatment plant commissioned in mid May 2006.

\subsection{Cost involvement}

Table 2 provides the costs of the above mentioned unit operation modules of the Mahiyangana water treatment plant based on 2006 rates.

Table 2 - Capital investment required for each treatment unit operation module of the Mahiyangana water treatment plant.

\begin{tabular}{|l|c|}
\hline \multicolumn{1}{|c|}{$\begin{array}{c}\text { Treatment module } \\
\text { (Capacity 500 } \\
\text { cubic meters/day) }\end{array}$} & Cost Rs. \\
\hline Sedimentation tank (Tube settler) & 550,000 \\
Chlorine contact tank & 200,000 \\
Rapid sand filter & 275,000 \\
\hline
\end{tabular}

\subsection{Conceptual drawings}

The conceptual drawings of the modules constructed are shown in Figures 9, 10 and 11.

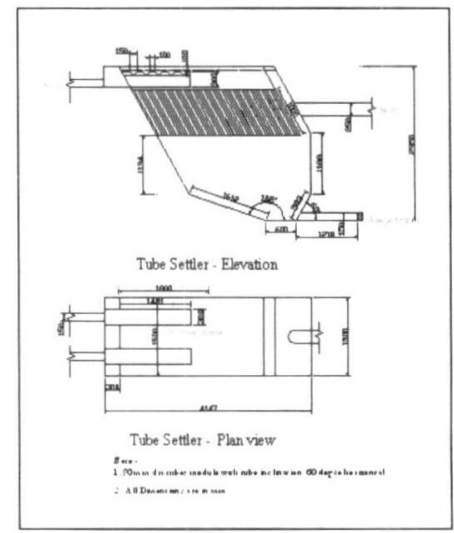

Figure 9: Conceptual Drawing of the Tube Setter

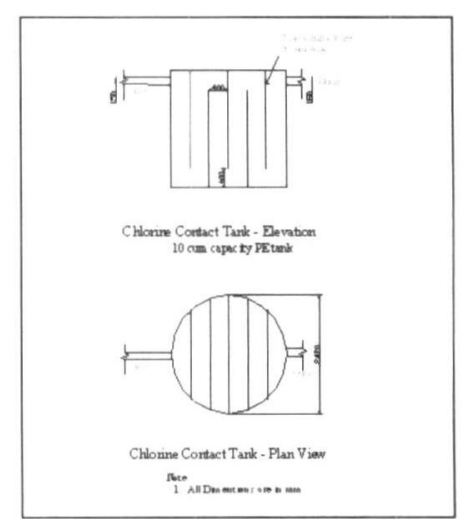

Figure 10: Conceptual Drawing of the Chlorine Contact Tank 


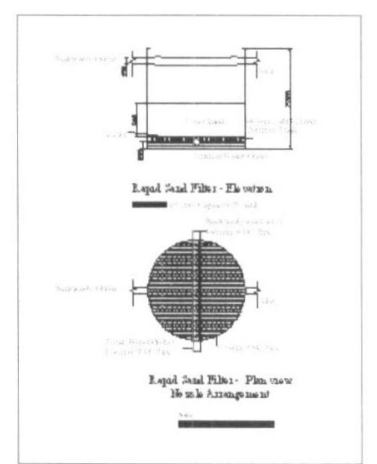

Figure 11: Conceptual Drawing of the Rapid Sand Filter

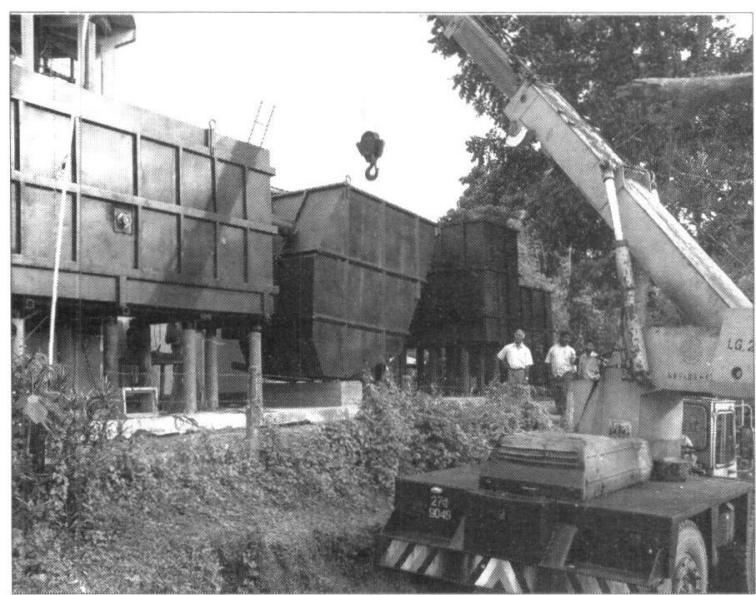

Figure 12: Pugoda treatment plant required 37 square meters of land for 500 cubic meters per day capacity.

\section{Conclusions}

Explained above is a much affordable anù sustainable technology for Sri Lanka which has scope for further improvement. Its advantages are

- Quick construction - Prefabrication of the units will further reduce the time required.

- Easy maintenance - Local technology does not involve complicated and costly imports.

- Less land requirement- As seen in Fig. 12.

- Movability - Easy to change treatment process modules to suit varying raw water qualities induced by poor environmental management.

- Helpful in upgrading water supply schemes with partial treatment.

- Quick solution for a disaster situation

One disadvantage is the unconfirmed product lifespan as this is a novel application. It is expected that the products will last for more than ten years if properly maintained.

\section{Acknowledgements}

The authors would like to thank the Chairman NWSDB, Mr. S.C. Amarasinghe for directing them to improve water supply schemes which distribute water of quality not meeting the Sri Lanka standards. General Manager NWSDB, Mr M. Wickramage for providing funds for these projects. Mr. S.K.S.H.K. Suriyaarachchi for continued encouragement on developing solutions for water sector in Sri Lanka using local skills and expertise. Mrs. M.K. Bandara and Mr. U.C. Pathiranage for completing the construction at Mahiyangana. Mr. D.I. Kannangara for supervising construction at Pugoda along with the Research and Development staff. Mrs. A.E. Gunawardena, Mr. S.G.Wickramatunge and the staff of the central workshop of NWSDB for their dedication on steel fabrication work.

\section{References}

1. Culp, G. Hansen, S. and Richardson, G. (1968), High-Rate Sedimentation in Water Treatment Works, Journal, American Water Works Association, New York, Vol. 60(06), pp 681-698.

2. Metcalf and Eddy (2003), Waste water engineering, Treatment and reuse, McGraw Hill, USA.

3. Visvanathan, C. (1999), Physico-Chemical Processes, Environmental Engineering Program, Asian Institute of Technology, Bangkok.

4. World Health Organization (2004), Guidelines for Drinkining Water Quality. Volume 1, Geneva, Switzerland.

5. Quasim, Q.R., Motley, E.M. and Zhu, G., (2004), Water Works Engineering, Planning, Design and Operation, Prentice Hall, New Jersey, USA

6. Posselt, H.S., Reidies, A.H. and Weber, W.J. Jr., (1968), Journal, American Water Works Association, New York, Vol. 60(01), pp 48-68.

7. Sommerfeld, E.O. (1999), Iron and Manganese removal handbook, American Water works Association, USA. 